\title{
Individualism and its Discontents: Man Alone in contemporary New Zealand.
}

\author{
Stephen Harris
}

The figure of Melville's monomaniacal captain, who would subdue all the forces of the world to the exigencies of his tormented mind, and who at any rate drives the living community on board the Pequod into oblivion in his obsessive hunt for "his" white whale, would not appear to be the obvious character to introduce a work of political analysis. But in Bruce Jesson's Only Their Purpose is Mad (1999) - the title is a loose adaptation of a line spoken by Ahab - this classic character makes a striking appearance. In seeing the nineteenth-century Ahab as representative of certain problems in our times, Jesson is as much interested in the role and influence of ideas as he is in examining the political causes of what he sees as New Zealand's on-going social ills. And in using this potently emblematic character from Melville's novel to illustrate his concerns, Jesson refreshes the seemingly outdated notion that literature - and the range of ideas generated therein - allows us revealing glimpses into the complex experience of our lives through altering the perceptual light through which we view our social-historical atmospheres. That Jesson's trenchant analysis is political in content and intent breathes vigour into his methods and prompts us be alert to the changes occurring around us. Looking at contemporary New Zealand in the presence, as it were, of the towering figure Captain Ahab, I found myself thinking more and more of John Mulgan's novel Man Alone and how this too, although aesthetically and stylistically opposite to Melville's massive tome, offers an interesting perspective on the present situation.

In performing what is essentially a critique of the ideology of the New Right in New Zealand, Jesson's interrogation has a broad reach, if only by implication. For his subject is in effect modern capitalism, the present freemarket competition model being the latest permutation of our Western way (a phenomenon now colloquially referred to in such generalising terms as globalisation and internationalisation). Jesson's principal concern is with the shift in political power as enacted in the New Right's auctioning off of New Zealand's economic, political and social "soul" to the faceless elite of global finance in the name of economic "rationalism". It is, he argues convincingly, an act of "madness", yet one performed according to the most rational of processes. This is the pivotal paradox, as characterised by Ahab, who is both the representative captain of the industrial, if not imperial, giant of the day - 
the powerful American whaling industry of the nineteenth century - and, in the dramatic terms of the narrative, the "insane" master of men. Grown grotesque in his hubristic excess - he is at once wounded Promethean, enraged Learian solipsist, and theatrical despot; his sin is to make a blasphemous god-head of his own pride and force his crew into self-sacrificial worship - we must also see that he is "captained" by his own indomitable will, that "unconquerable captain in the soul" (Melville, 671) as Melville has him phrase it. ${ }^{1}$ Ahab, then, effects a destructive distortion of his individual self; or, to touch on a crucial distinction, his individuality is transposed to a political dimension - he creates, organises and dictates a system of sorts, however "mad", around his enraged self. The protagonist in Mulgan's novel also creates and lives by a system, and although it is to all appearances wholly different to Ahab's, I would argue that in terms of its political significance, it stands in complementary relation.

As errant commander, disengaged from the regulating forces of land-borne institutions, Ahab perverts both the function of the ship-board community and the purpose of the industrial hunt; and if the men are cruelly subordinated to his will, this, to some extent, occurs through their being seduced into believing they have been elevated to the ennobling sphere of Ahab's all-commanding personae - absorbed into the idea of a man who is himself ultimately defined by an idée fixe. Melville exaggerates this aspect of Ahab for what are very effective dramatic purposes; but for Jesson, Ahab serves to symbolise the negative social effects of the New Right politics - the disabling of New Zealand's productive economic capabilities and the fragmentation of community as a result of a similarly "mad" political system - a set of practices at whose ideological heart is a destructive form of individualism.

It is this view of individualism as promoting and installing a potentially destructive idea of self that I think is interesting, partly because individualism (broadly speaking) is such an integral aspect of our Western cultural selves, and so is something we are apt to overlook, or whose importance we are inclined to downplay. Strictly speaking, individualism denotes a social theory that determines the degree of freedom permitted for the definition of self; but as the term itself clearly indicates, this social theory is predicated on the idea of the individual and individuality; and since the idea of the individual is the conceptual cornerstone of Western culture, we all to some extent or another

\footnotetext{
${ }^{1}$ Alive, like its narrator, Ishmael, with the "riddles of the universe", Moby Dick is oceanic in imaginative scope. A vast and heretical fusion of epic, comedy, tragedy, adventure story, seafaring yarn, tall tale and philosophical treatise, rushing and swirling with dramatic incident, rhetorical virtuosity, metaphor and symbol, Moby Dick also achieves a unity that springs out of an inner dynamic of paradox and antinomy. In many ways, Ahab - "insanely" rational, calmly contemplative in his "madness", thus the embodiment of these constitutional contrarieties - is the centre of the novel, the commanding figure in every sense of the word.
} 
conceive of ourselves and our immediate worlds according to this creed notwithstanding the on-going contemporary critical obsession with proclaiming and anatomising the "death of the bourgeois subject". Since it is implicit and fundamental to so much of what we take for granted, the finer degrees of this constitutive individualism can be difficult to discuss clearly and with any conceptual precision, although there is a vast body of theoretical literature devoted to this very task. Moreover, while we can see examples of individualism in much of our cultural surrounds and in many aspects of our interior makeup, to suggest that we can cleanly isolate this element, however fundamental, from other features of society is inevitably a little misleading. For this reason, complex figures such as Captain Ahab - Mephistophelian "hero", paradoxically noble in his sacrilegious tyranny; compelling in the pernicious extremities of his self-exceptionality - can help focus our critical attention in ways that sociological discussion can not always achieve.

In critical commentary, Ahab is routinely described as a character in whom are concentrated the motivating energies of expansionist capitalistic America in the nineteenth century and, in what is essentially inseparable, the ideology of American individualism that is so fundamental to the American character. That this "imperial self" is both a creature of fiction and of another era, might seem reassuring; yet, to extend on Jesson's idea by way of a speculative question, is it possible to see this "character" being reanimated today in a far more generalised form? That is, in contemporary New Zealand, and in the individualism that Bruce Jesson speaks of as having arisen via the ascendency of new right politics over the last fifteen years, are we witnessing the transformation of the "imperial" frontier stereotype of the eighteenth and nineteenth centuries, in effect both a magnification and crystallisation of the Western "way" as it is remodelled and readapted for its guiding role in the new internationalised global order? And does this, then, mark the "imperialistic" triumph of American culture, whose political and cultural influence it is difficult to argue with? For many, as this ineluctable process of globalisation threatens to erase identity-defining borders, questions such as these are pressing. It is not my intention to attempt any sort of comprehensive answer here; however, what I would like to suggest is that John Mulgan's Man Alone attains a renewed relevance in light of the sort of connection Jesson outlines, for what it offers the contemporary reader is a critical and sharpened perspective on individualism - on the fundamental ways in which we conceive of, and the assumptions we harbour about, ourselves - and, by extension, the manner in which, in certain distorting ways, it is used to underwrite predominating political practices.

In New Zealand, as in other modern Western democratic societies, concerns about what are seen as destructive strains of individualism have 
erupted periodically. For various reasons, the balance between the rights and freedoms of individuals and the demands and obligations of society is thrown out, with complaints most often surrounding concerns about pernicious bouts of self-interest, narcissism and communal inadequacy amongst the populace (the classic liberal ideal of enlightened self-interest is vulnerable to what some see as the corruptions of vulgar, self-gratifying materialism - the effects of the citizen/consumer exercising freedom of choice and self-expression). And, while we are, and need to be sensitive and alert to an overly coercive and intrusive state, there is the other extreme with which we are all familiar, and which is encapsulated in Margaret Thatcher's much-quoted claim that there is no such thing as society - the New Right individualism that asserts a far more direct link between the individual and the overarching ideology of nationalism. This points to the paradoxical issue that concerns Jesson, the situation in which a destructive form of individualism is imposed on the community, a move that is sanctioned through the self-justifying logic of democratic rights that safeguard and enhance individual freedom.

From such positions, the ensuing discussions inevitably tap into a vast matrix of interrelated moral, ethical and political issues, and, as has been the case in America for the last ten years, the debate is often rehearsed under the crudely simplistic rubric of "communitarianism vs. individualism" (while on the broader social and political front there is the fractious tussle of "identity politics".) While on the theoretical and philosophical level there are different shadings and categories of individualism, in practice, as it were, there is a waxing and waning of emphasis due to social and political and economical circumstances. At present, it is orthodox to assert the "social constructivist" and purportedly liberating notion that we consist of a plurality of possible selves, since the very notion of the individual is an ideological myth, preventing us from claiming an absolute essence, or irreducible centre, of self. This might be called the New World syndrome: in being freed from the traditional (Enlightenment) idea of the self, we can (it is implied) endlessly and effortlessly "construct" versions of our selves appropriate to the circumstances. It can also be viewed as a clever marketing ruse: to see our identities in terms of exchangeable "products" deftly prepares us for the everexpanding market of postmodernity by discouraging us from acting and thinking according to principals that exist beyond the imperatives of commodity flow.

Clearly, the issue is knotty, and has as much to do with the tendency towards the programmatic application of ideas as it does with the core concept of the individualised self. Indeed, Melville's Promethean "superman" underlines the extent to which a cult of the individual arises so successfully: the idealised heroic individual, exemplary in their self-governing uniqueness, 
is always the potential autocrat, one who would suppress another's genuine individuality - in the sense of being not simply corporealy distinct, but intellectually and politically independent of thought and action, and thus possessing the right to resist - in the process of coming into full possession of their selves. To point towards the principal and essentially metaphysical theme in Mulgan's novel, it is also important to remember that (after Milan Kundera) being is not necessarily synonymous with being one's self. Investigating the myriad aspects of this condition (and conditioning) of being of the manifold particularities and dimensions of self - is the stuff of a great deal of fiction: Kundera, echoing D.H.Lawrence and Walter Benjamin, defines the novel precisely in terms of its prolonged attempt to answer the questions, "What is an individual? Wherein does his identity reside?". In his extended dramatisation of the destructive forces associated with one man's claim to a sovereignty of self in Moby Dick, Herman Melville provides an example of what many others have, from across a vast stylistic spectrum, touched on in their fiction.

In showing us how the character Ahab stands as a metaphor for dominating aspects of our contemporary experience, Jesson also encourages us to look around the cultural landscape for revealing signs. Across the shifting panorama of popular culture, the interested observer can find a great variety of images on a multitude of cultural surfaces reflecting the ethos of individualism; arguably, even the increasingly challenged model of the nuclear family is primarily individualistic in concept. Amongst these common-place, mass-marketed appeals to our sense of individuality, some speak more directly than others of the ever-seductive idea of power in the form of indomitable selfhood, of self-command and the commanding self, although few, if any, exist on Ahab's scale of theatrical magnitude. What I have noticed, and what may well be the result of the shifting political energies and order of Western capitalism in the early twenty-first century, is a certain severity of tone in the popularised image of selfhood. In advertising and the televisual media, the defining images of contemporaneity evince a shrewdly efficient containment or molding of energy and will, a business-like harnessing of vitality into a hardened shell of self-projection. Missing is any sense of celebration or inner elation, of imminent abandonment and release, of actually enjoying this state of affirmative individuality, however simulated that may be. There is no sense of liberating bohemianism, of ludic antinomianism, no fluster of innocent recklessness ruffling the posture. If there is some ontological solace to be gained through believing in our essential and inviolable individuality - and there is nothing we respond to with such instinctual alacrity as this comforting idea of our free and empowered selves - 
this aura of mutedly grim determination introduces a conspicuously compromising tone.

What I take to be this pervasive mood of oddly solemn self-possession puts me in mind of the character Johnson, the "lone man" in John Mulgan's novel, Man Alone (1939). As the title suggests, there is a central existential theme in this novel, and as Lawrence Jones argues in The Oxford History of New Zealand Literature, Man Alone initiated a trend, if not a "genre", in modern New Zealand fiction (with Kundera's statement in mind, this suggests the interesting idea that the novel in New Zealand has developed a culturally specific character in terms of its preoccupation with and treatment of an existential theme). At one point, as Johnson prepares for flight in the wake of what will be contrued as his murder of the farmer Stenning, we are told of his thoughts concerning his life to this point in New Zealand (circa 1930s): "If he could get away he could keep some things. He could keep the one thing he had had in all the years he had known this country, and that was the freedom to go and to work and to live where he liked" (127). For those of us who put our faith in democracy, this description of New Zealand would certainly make it, politically and socially, "God's own country" - although, as the subjunctive tense suggests, for Johnson, it is, in a sense, already in the past. What is expressed here is a philosophical commonplace: the liberty to be one's individual self is inseparable from the freedom to move and act at will and on whim (even if that means having to work - a fact which touches on latent philosophical questions concerning the very concept of freedom itself). But what I find curious is the possessive language Mulgan uses, by which freedom becomes a material "thing" that his character in some sense owns. Linguistically, it is not unusual to think of "having" (and thus losing) one's freedom; but this is a little different to "being" free. It is a distinction that is brought out somewhat obliquely in the novel: notwithstanding Mulgan's "objective" and starkly understated literary style and detached third person narration, Johnson is never described as experiencing within himself an empowering condition of free agency. That is, he is never shown to have - in any convincingly dramatic sense - the very thing he fears losing.

This might indicate a logical or structural inconsistency in the narrative, an impression that is reinforced by the fact that, given the freedom and opportunity of the time and place, Johnson is not seen to be motivated by any drive to be successful in the manner that is common among others he meets. Described at one point early on as feeling "strong" and "alive" because he was "in charge of himself" (36), his entire manner is one of a curious ambitionlessness. When he describes his "system" of living - "it's the keep on working and moving, it's the hard work for the good time and never stay long anywhere" (44) - there is never any sense of invigorating aimlessness in his 
picaresque mobility. We could read this in terms that are closer to the existentialist literary tradition, and yet Johnson never appears to be a vehicle for Mulgan to explore and test, in a fuller dramatic sense, the philosophical concept of freedom and the shifting modulations of identity - Johnson does not act in a way that indicates an attempt to understand in some fundamental way his self in existence. It is as if he doesn't know what to do with himself; or, as I want to contend, does not know in any fully conscious way how be his self, or rather the self that he feels in some way he should be. Instead his sense of freedom and thus self is a reductively negative or defensive one; initially goaded by an incurable restlessness to which he submits with a weary resignation (until he is driven by fear of incarceration), he keeps on the move and largely to himself. In fact, the general tone and atmosphere of the novel reinforces this: the narrative is so thoroughly suffused with an enervating despondency that Johnson seems only ever to endure the "free" life he leads up until his "escape" mid-way through the novel.

In being reduced to such existential bare essentials - this is the dramatic and philosophical core of the novel - his desire to retain possession of his freedom actually reinforces what, as is conveyed in the novel's sullen refrain, is his self-defeating aloneness: "Most of the time a man spends too much alone" (205). What, then, if it can in any way be said to exist, is the real nature of the freedom Johnson wants to protect? Entwined as it is in the compulsion to be "alone", are we then compelled to review the very idea of the free self as embodied in Mulgan's protagonist, just as Johnson, during his struggle in the bush, comes "to hate the heavy silence of the bush ... where before he had welcomed it as a sanctuary" (144)? In evading both capture and death through exposure, Johnson is not shown to emerge bristling with Promethean pride, the lone and romantic hero as bastion of true and just values; ${ }^{2}$ and we never get any convincing sense that he emerges from his trial having learnt uplifting or edifying lessons of humility and self-denial through hardship - that will power and discipline are valuable qualities of character for life in the frontier. Underlining this is the fact that the isolated moments in which Johnson experiences what are described as quickening feelings of community - amongst the gathering of protesters on the way to the Queen Street riots and in the company of Jack O'Reilly as they prepare to leave for the Spanish Civil War very near the end of the novel - are instances that both arise out of, and will be immediately dissolved in, violence (in the latter case, it is implied rather than actual, as it occurs off-stage). While we can see in these fleeting

2 In his introduction to the Penguin edition (1990), Patrick Evans argues that the novel appeals to us fifty years after its publication as "a powerful example of male romanticism" ( $p$. v), an argument which I find unconvincing. 
and doomed "unions" an unarticulated relief that arises out of the "freedom" not to have to go it entirely alone - not to have to continually make the exhausting existential decision to be "free" - the conspicuous and troubled transience of these "connections" would appear to scratch a nihilistic line through the very idea of fraternity. The dramatic and philosophical implications of the loss of his freedom must be measured against these characteristics of the novel.

Before elaborating on what I feel is a compellingly odd and fundamental irresolution in the text, a quality that makes Mulgan's novel all the more interesting in terms of offering a provocative view on individualism, it is important to acknowledge several other factors. It should be said that in the context, the deflating mood and tone of the novel makes a certain sense, since, most immediately, Johnson, like many of the people he meets in this time of troubled mid-war peace, faces the prospect of dispossession, be it land or the opportunity to earn a wage. ${ }^{3}$ It is a condition brought about by the wider historical and cultural forces impinging upon both protagonist and author - the political and economic effects of the Depression coupled with a mid-war anxiety. The peculiar thinness of the narrative is further reinforced through Mulgan's attempt at writing with Hemingwayesque "masculine" empirical directness; in fact, for some, this might represent an aesthetic shortcoming in that this style prevents by its very nature any fuller exploration and evocation of character. ${ }^{4}$

Beyond these factors, the most influential way of explaining Man Alone is in terms of social critique. Lawrence Jones endorses the common view that Mulgan's depiction of the alienated individual is a means of criticising the repressive forces of a conformist puritanical society. Johnson's existentially and spiritually impoverished existence, then, is a direct product and indicting reflection of a life-denying society - a concern that becomes a "favourite provincial theme" in New Zealand fiction (Jones 203, 157). While Jones reminds us that contemporary novels focus less on the repressive wrongs of society and more on the inner existential struggle, what needs to be said is that this sort of dichotomy has an almost archetypal appeal to those of us reared in societies in which individualism is of a primary importance.

I'm not so sure it is a simple matter of there being a clash between a monolithic and shackling community and the sensitive individual, in and through whose struggles we can gauge the condition of society (Jones in Sturm, 164). After all, this romanticises the individual (expand); also, this

\footnotetext{
${ }^{3}$ There is something of a bleak irony at work here as suggested by Johnson's comment, "I've been in wars, there's nothing in them. The peace is more dangerous"(204).

${ }^{4}$ It could also be argued that Mulgan was not able to screen out his own tacit nihilism, one which may have propelled him to his suicide in 1945.
} 
approach places the emphasis on the individual being condemned to an isolating "freedom" or alienation, whereas Mulgan's "man alone" is frequently described as preferring and cultivating dissociation - his "system" that dictates freedom of choice and movement and yet which is actually enervating. This is peculiarly irrational and contradictory since it is not given dramatic support or justification in the novel (he is does not act in rebellion or subversion). When, near the end, we and he are left with his perplexed realisation that his life has been governed by "a restlessness that would not leave him in peace" (196), I think it is plausible to contend that Johnson has been suffering throughout an unconscious disillusionment with, and existential incapacity in the face of the idea of him self as a free agent. To put this another way, the promise of autonomous selfhood and the untrammelled freedom with which this correlates cannot satisfactorily translate as lived fulfillment. This not stated in any dramatically explicit sense; rather, just as Johnson at the beginning and end of the novel ominously refers to "the bit in between" the two wars - the "dangerous" peace that is his life in New Zealand, the very subject of Mulgan's narrative (6/204) - so the novel, in never convincingly evoking Johnson's experience of being free in "God's own country", states the case through, as it were, an absence. One significant reason for this peace being "dangerous" is that it puts the issue of life, of self and purpose, in existential relief: released from the cohering forces of war - that grim paradox of purposeful and uniting violence - Johnson is alone in the most confronting and challenging of ways, for he is alone, and, in a sense at a complete loss with, his "free" self; or more importantly, with the idea and ideal of autonomous selfhood. What Mulgan's novel achieves, then, in its odd irresolution is a pressing sense of ambiguity about the very idea of individualistic self. It does not propose alternative models but rather brings the very idea of self into focus, albeit obliquely. Like Melville's great novel, in which the famous narrator Ishmael comes to understand through his fraternal bond with Queequeg a new way of seeing his self - one in marked contrast to the rampant individualism of Ahab - so Mulgan's novel, in an invertedly complementary way, offers us a quirky meditation on being one's self.

My purpose here has not been to either implicitly disavow or celebrate some notion of pure individuality or to tacitly idealise the idea and experience of community. The complexity of contemporary life renders such aims impossible, at least for those who want to think beyond politically fundamentalist platitudes. But that such platitudes exist and influence our lives is the very point. After all, the idea of our exalted uniqueness as propagated endlessly by our commodifying free-market societies becomes, all too easily, a deceiving mythology that substitutes a superficial and spurious set of consumer rights for the more important political rights of the citizen. That most 
of us are now familiar with what might be called the dubious politics of individualism that are central to the New Right agenda should give us cause for concern. Translated to the political rhetoric of these linguistically blighted days, we can see words such as "freedom" and "individual rights" growing distorted in sense, words that are used to justify the "liberating" of thousands of care-dependent people to the streets in the name of "deinstitutionalisation", to argue for the abolition of unions in the name of "free enterprise" and to worship the mythicised coterie of rich and famous "winners" as models of desirable selfhood. In the same way, and given what appears to be the inexorable and America-lead globalisation of economies and thus cultures, we need to be attentive to the discrepancies between the language and ideas promoting these developments and the local, political realities. And while it is attractive, and overly easy for that reason, to see the broad sweep of Western culture as a new form of American-style frontierism and its emphasis on individualism, it is novels such as Moby Dick and Man Alone that encourage us to be sceptical about the ideas that are intrinsic to our culture.

\section{Works Cited:}

Jesson, Bruce. Only Their Purpose is Mad. Palmerston North: The Dunmore Press, 1999.

Jones, Lawrence in Terry Sturm (ed.) The Oxford History of New Zealand Literature in English. $2^{\text {nd }}$ edn. Auckland: Oxford University Press, 1998.

Melville, Herman. Moby Dick. Ed. Harold Beaver. Harmondsworth: Penguin Books, 1972.

Mulgan, John. Man Alone. London: Penguin Books, 1990. 